\title{
The year at Future Cardiology
}

\author{
Julia Titova*,1 (iD) \\ ${ }^{1}$ Future Science Group, Unitec House, 2 Albert Place, London, N3 1QB, UK \\ *Author for correspondence: j.titova@futuremedicine.com
}

\begin{abstract}
"The editorial office would like to thank all our authors, readers, peer reviewers and editorial board members for their continued support in what has been a challenging year for many of us."
\end{abstract}

First draft submitted: 28 September 2020; Accepted for publication: 28 September 2020; Published online: 24 December 2020

Keywords: cardiology • chronic heart failure • COVID-19

Welcome to Volume 17 of Future Cardiology. The editorial office would like to thank all our authors, readers, peer reviewers and editorial board members for their continued support in what has been a challenging year for many of us. In this Foreword, I would like to present some highlights from the past year as we look forward to our continued partnership in 2021.

\section{COVID-19}

Many of you have been at the forefront of fighting the global pandemic that has engulfed the world. Future Cardiology would like to thank those who have been contributing their research toward this ongoing battle, and those who have been working directly with affected patients. During this difficult time, we have published some fascinating papers on this topic.

This issue also contains some very interesting papers, highlighting just how many different aspects there are to this disease. Bhurint Siripanthong et al. discuss the delay in the diagnosis and management of chest pain, acute coronary syndromes, myocarditis and heart failure, which is being caused across the world [1]. On the other hand, Justin Hall provides us with an opportunity to look forward to the changes that the current situation might bring. His editorial 'The impact of COVID-19 on critical cardiac care and what is to come postpandemic' suggests some interesting innovations that might be accelerated due to this global health crisis [2].

\section{Authorship demographics}

As every year, we have seen a huge number of outstanding submissions from all over the world and have been encouraging submissions from communities under-represented in the field of cardiology. Figures $1 \& 2$ highlight the change in authorship demographics in the last year. The USA continues to provide the greatest number of manuscripts, with the UK and Italy also contributing large numbers of papers. In particular, this year we have seen an increase in the number of papers published from Germany, India and Iran.

\section{Content highlights}

Our top read article during this time (as of October 2020) has been a case series entitled 'Sudden cardiac death in COVID-19 patients, a report of three cases' by Samira Shirazi et al. [3]. The case series outlines the possibility of development of sudden cardiac arrest in COVID-19 patients and highlights yet another devastating impact of this disease.

Of note, the 2018 Commentary 'Depression and anxiety in patients with chronic heart failure' by Bruno Bordoni et al. [4] has also been extremely popular with our readers in the last couple of years. The authors explore the potential role of the diaphragm in chronic heart failure and emotional effects this may have on patients.

\section{Social media}

Future Cardiology remains active across social media and you can follow our latest updates on Twitter (@FsgFCA) and LinkedIn. We encourage authors to share their work on social media channels, attracting greater readership

Future $\because$ Medicine 

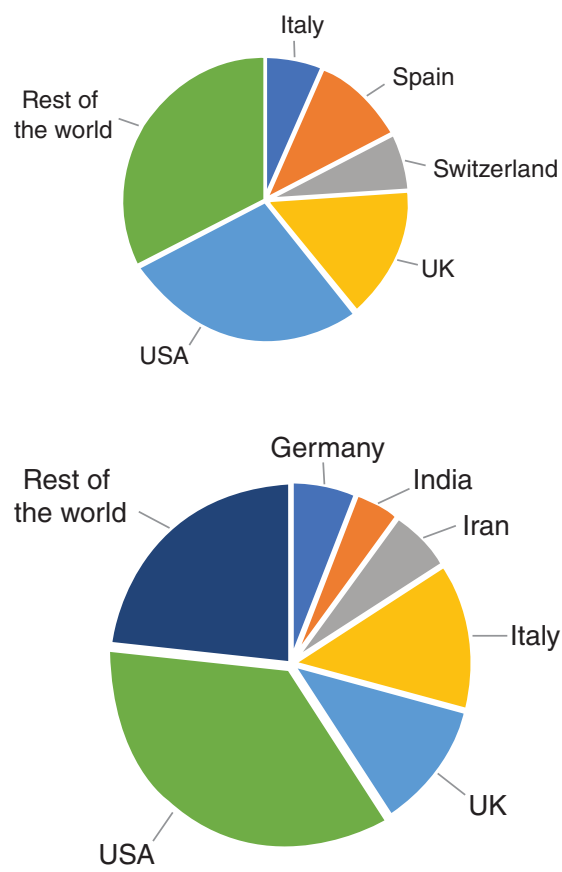

Figure 1. Authorship demographics in 2019, showing countries with highest number of papers accepted for publication.

Figure 2. Authorship demographics in 2020, showing countries with highest number of papers accepted for publication.

of our superb content. As we enter 2021, we will continue to post about the work of our amazing authors and encourage you all to share peer-reviewed papers to further all areas of cardiological research.

\section{Editorial board}

This year we have said a difficult goodbye to one of our exceptional editorial board members, Dr Francis Robicsek, who passed away in April 2020 aged 94 years. We greatly appreciate his work for Future Cardiology.

We have been joined by several new editorial board members over the past year and look forward to working with Professor Craig Coleman, Professor Gregory Lip, Professor Marco Proietti, Dr Dhanunjaya Lakkireddy and Dr Erik Wissner.

\section{Conclusion}

As always, we welcome any feedback that you might have about the work of the journal and anticipate having the opportunity to expand we do in the next year, continuing to bring high quality papers to the cardiological community and beyond. We would be equally delighted to consider unsolicited research and review articles and would be happy to discuss your ideas with you.

Once again, thank you for supporting Future Cardiology. We look forward to collaborating with many of you in the coming year and wish you all the very best for 2021 .

Financial \& competing interests disclosure

J Titova is an employee of Future Medicine Ltd. The author has no other relevant affiliations or financial involvement with any organization or entity with a financial interest in or financial conflict with the subject matter or materials discussed in the manuscript apart from those disclosed.

No writing assistance was utilized in the production of this manuscript.

\section{References}

1. Siripanthong B, Hanff TC, Levin MG et al. Coronavirus disease 2019 is delaying the diagnosis and management of chest pain, acute coronary syndromes, myocarditis and heart failure. Future Cardiol. 17(1), 3-6 (2020).

2. Hall J. The impact of COVID-19 on critical cardiac care and what is to come postpandemic. Future Cardiol. 17(1), 7-10 (2020).

3. Shirazi S, Mami S, Mohtadi N et al. Sudden cardiac death in COVID-19 patients, a report of three cases. Future Cardiol. 17(1), 113-118 (2020).

4. Bordoni B, Marelli F, Morabito B, Sacconi B. Depression and anxiety in patients with chronic heart failure. Future Cardiol. 14(2), 115-119 (2018). 